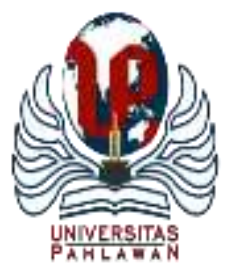

Edukatif : Jurnal Ilmu Pendidikan Volume 4 Nomor 1 Tahun 2022 Halm 1349 - 1357

EDUKATIF: JURNAL ILMU PENDIDIKAN

Research \& Learning in Education

https://edukatif.org/index.php/edukatif/index

\title{
Adopsi Teknologi Informasi dan Knowledge Sharing: Analisis Mediasi Budaya Organisasi
} di Perguruan Tinggi

\author{
Erni Taruli Pebrina ${ }^{1 凶}$, Rachma Nadhila Sudiyono ${ }^{2}$, Suroso $^{3}$, Dewiana Novitasari ${ }^{4}$, \\ Masduki Asbari ${ }^{5}$ \\ Sekolah Tinggi Ilmu Ekonomi Insan Pembangunan, Indonesia ${ }^{1,2,4}$ \\ STMIK Insan Pembangunan, Indonesia ${ }^{3,5}$ \\ E-mail : ernipebrina@gmail.com ${ }^{1}, \underline{\text { rachmanadhila94@gmail.com }}^{2}, \underline{\text { suroso.ip@gmail.com }}^{3}$, \\ dhewiediosa@yahoo.co.id ${ }^{4}$, kangmasduki.ssi@gmail.com ${ }^{5}$
}

\begin{abstract}
Abstrak
Tujuan dari penelitian ini adalah untuk mengetahui pengaruh adopsi teknologi informasi terhadap niat berbagi pengetahuan dengan melibatkan budaya organisasi sebagai mediator. Sampel penelitian ini diambil dari 102 orang dosen salah satu perguruan tinggi swasta di Indonesia dengan menggunakan teknik simple random sampling dan menggunakan SEM (Structural Equation Model) dengan software SmartPLS versi 3.0 sebagai alat statistiknya. Hasil penelitian ini menunjukkan bahwa adopsi teknologi informasi berpengaruh positif dan signifikan terhadap knowledge sharing intention, baik secara langsung maupun melalui mediasi budaya organisasi. Oleh karena itu, budaya organisasi dapat menjadi variabel mediator yang memperkuat pengaruh adopsi teknologi informasi terhadap niat berbagi pengetahuan.
\end{abstract}

Kata kunci: Adopsi teknologi informasi, budaya organisasi, knowledge sharing.

\section{Abstract}

The purpose of this study is to investigate the effect of information technology adoption on knowledge sharing intention by involving organizational culture as a mediator. The sample of this research was taken from 102 lecturers of a private university in Indonesia using a simple random sampling technique and using SEM (Structural Equation Model) with SmartPLS version 3.0 software as a statistical tool. The results of this study indicate that information technology adoption has a positive and significant effect on knowledge sharing intention, either directly or through organizational culture mediation. Therefore, organizational culture can be a variable mediator that strengthens the influence of information technology adoption on knowledge sharing intention.

Keywords: Information technology adoption, knowledge sharing, organizational culture.

Erni Taruli Pebrina, Rachma Nadhila Sudiyono, Suroso, Dewiana Novitasari, Masduki Asbari

$\triangle$ Corresponding author:

Email : ernipebrina@gmail.com

DOI : https://doi.org/10.31004/edukatif.v4i1.2223 
1350 Adopsi Teknologi Informasi dan Knowledge Sharing: Analisis Mediasi Budaya Organisasi di Perguruan Tinggi - Erni Taruli Pebrina, Rachma Nadhila Sudiyono, Suroso, Dewiana Novitasari, Masduki Asbari

DOI: https://doi.org/10.31004/edukatif.v4i1.2223

\section{PENDAHULUAN}

Teknologi informasi (TI) tidak hanya menyediakan lebih banyak saluran untuk berbagi informasi, tetapi juga mengurangi hambatan arus informasi, dan karenanya meningkatkan pembagian informasi proses (Aman \& Asbari, 2020; Tiara et al., 2021). Aspek paling berharga dari TI dalam manajemen pengetahuan (KM) memungkinkan perluasan dan universalisasi ruang lingkup pengetahuan, dan peningkatan kecepatan transfer pengetahuan. TI dengan demikian memainkan peran penting dalam mempromosikan pengetahuan berbagi, meskipun dukungan dari manajemen puncak diperlukan bagi organisasi untuk menerima, mengadopsi, dan mengimplementasikan proyek TI (Jarmooka, 2021; Soto-Acosta, 2018). Studi sebelumnya tentang IT adopsi telah didasarkan pada perspektif individu dan organisasi untuk menyelidiki kemauan untuk memanfaatkan TI. Dari perspektif individu, sebagian besar studi didasarkan pada Technology Acceptance Model (TAM) dan menyelidiki bagaimana individu pengambil keputusan pengetahuan dan sikap mempengaruhi adopsi TI. Dari perspektif organisasi, banyak penelitian telah meneliti latar belakang organisasi, budaya, faktor teknologi, dan lingkungan eksternal untuk menyelidiki masalah utama di balik TI organisasi adopsi (Mohammadi, 2015). Namun, ada beberapa penelitian yang mengambil baik individu maupun faktor organisasi menjadi pertimbangan ketika memeriksa hubungan antara niat adopsi TI dan niat berbagi pengetahuan. Selain itu, dukungan budaya organisasi mempengaruhi cara karyawan berpikir, bertindak, dan menanggapi misi perbaikan proses (Fathema et al., 2015). Selain itu, terdapat pengaruh dukungan budaya organisasi dan perilaku karyawan terhadap berbagi pengetahuan (Asbari et al., 2021; Fikri et al., 2021; Hutagalung et al., 2021; Novitasari et al., 2021; Purwanto, Bernarto, et al., 2020; Singgih et al., 2020; Suroso et al., 2021). Budaya organisasi yang berbeda dapat mempengaruhi keinginan anggota untuk berbagi pengetahuan, dan perusahaan dengan demikian harus lebih lanjut mengidentifikasi budaya apa yang lebih baik mendukung berbagi pengetahuan sebagai aktivitas alami dalam pekerjaan sehari-hari dosen.

Mengingat peran penting budaya organisasi dalam TI adopsi dan berbagi pengetahuan, tujuan dari penelitian ini adalah untuk menjawab pertanyaan: Bagaimana adopsi TI dan niat berbagi pengetahuan dalam kaitannya budaya organisasi? Dengan mengatasi kesenjangan ini dalam penelitian sebelumnya, penelitian ini berusaha membuat tiga kunci kontribusi. Pertama, penelitian ini mencoba untuk memperkaya penelitian tentang efek kompleks dari keterlibatan IT pada niat adopsi TI, dan niat berbagi pengetahuan. Oleh karena itu, ini penelitian didasarkan pada konsep keterlibatan TI dan menyelidiki apakah niat adopsi TI mempengaruhi niat berbagi pengetahuan. Kedua, studi ini berfokus juga pada variabel inti, yaitu budaya organisasi sebagai variabel moderator antara adopsi TI dan niat berbagi pengetahuan. Dengan kata lain, penelitian ini berpendapat bahwa niat adopsi TI dapat meningkatkan niat berbagi pengetahuan melalui mekanisme budaya organisasi. Ketiga, penelitian ini mengusulkan saran konkrit yang dapat digunakan sebagai referensi oleh perguruan tinggi yang ingin meningkatkan kesediaan dosen dan staf untuk berbagi pengetahuan. Sehubungan dengan keterbatasan penelitian sejenis yang dilakukan di Indonesia dengan unit analisis Pendidikan tinggi swasta, maka hasil penelitian ini diharapkan akan menjadi basis dari penelitian-penelitian selanjutnya di Indonesia.

\section{METODE PENELITIAN}

Menurut Creswell \& Creswell (2017), jika tujuan dari penelitian ini adalah untuk mengetahui hubungan pengaruh antar variabel yang diteliti, maka pendekatan kuantitatif adalah yang terbaik. Metode penelitian kuantitatif adalah cocok dalam menguji teori dan hipotesis melalui penggunaan seperangkat alat statistik (Creswell \& Creswell, 2017). Oleh karena itu, penelitian ini menggunakan metode survei untuk menguji hipotesis yang dirumuskan. Oleh karena itu, diadopsi kuesioner digunakan sebagai instrumen untuk mengumpulkan data yang dibutuhkan. Populasi penelitian terdiri dari 1205 mahasiswa di perguruan tinggi 
1351 Adopsi Teknologi Informasi dan Knowledge Sharing: Analisis Mediasi Budaya Organisasi di Perguruan Tinggi - Erni Taruli Pebrina, Rachma Nadhila Sudiyono, Suroso, Dewiana Novitasari, Masduki Asbari

DOI: https://doi.org/10.31004/edukatif.v4i1.2223

swasta di Tangerang. Dengan menggunakan simple random sampling, 1205 kuesioner dikirim secara online kepada populasi. Sebanyak 1026 kuesioner dikembalikan dan valid, yang membentuk tingkat tanggapan $85,1 \%$. Oleh karena itu, manurut Roscoe et al. (1975) jumlah sampel yang diperoleh sudah sangat memadai.

Sifat penelitian ini melibatkan efek dependen antara konstruk laten dan variabel manifest, oleh karena itu, model pengukuran reflektif cocok untuk penelitian ini (Hair Jr et al., 2017). Semua item yang diadopsi dinilai pada skala Likert lima poin dari 1 (sangat tidak setuju) sampai 5 (sangat setuju). Instrumen adopsi teknologi informasi (ATI) terdiri dari 3 item (ATI1- ATI3) diadaptasi dari Tseng (2017). Instrumen untuk mengukur knowledge sharing terdiri dari 5 item (KS1-KS5) mengadaptasi dari Tseng (2017). Instrumen untuk mengukur dukungan budaya organisasi terdiri dari 4 item (DBO1-DBO4) mengadaptasi dari Lukes \& Stephan (2017).

Teknik statistik paling populer di bawah Structural Equation Model SEM adalah berbasis kovarian pendekatan (CB-SEM) dan teknik kuadrat terkecil parsial berbasis varian (PLS-SEM) (Sarstedt et al., 2014). Namun, PLS-SEM akhir-akhir ini mendapat perhatian yang luas di banyak orang disiplin ilmu seperti pemasaran, manajemen strategis, sistem informasi manajemen, dan cabang keilmuan lainnya (Hair et al., 2012). Kemampuan PLS-SEM untuk menangani permasalahan problematic modelling yang biasa terjadi di lingkungan social ilmu pengetahuan seperti karakteristik data yang tidak biasa (misalnya data non-normal) dan model yang sangat kompleks adalah alasan penting di balik peningkatan penggunaan pendekatan ini. Mengingat keuntungan dari pendekatan ini, penelitian ini menggunakan PLS-SEM untuk menguji secara keseluruhan dari hipotesis yang diajukan. Perangkat lunak SmartPLS 3.0 dilakukan untuk mengevaluasi masing-masing outer model dan inner model. Pengujian outer model dilakukan untuk memastikan keandalan dan validitas pengukuran, sedangkan hipotesis yang diperkenalkan diperiksa melalui inner model. Selanjutnya, hasil akhir kuesioner yang kemudian digunakan pada penelitian ini sebagaimana disebutkan pada Tabel 1.

\section{Tabel 1}

Daftar Item Penelitian

\begin{tabular}{|c|c|c|}
\hline Notasi & Item & Referensi \\
\hline \multicolumn{2}{|c|}{ Adopsi Teknologi Informasi (ATI) } & Tseng (2017) \\
\hline ATI1 & $\begin{array}{l}\text { Saya berniat menggunakan fasilitas IT yang dapat membantu saya berbagi ilmu } \\
\text { dalam waktu dekat. }\end{array}$ & \\
\hline ATI2 & $\begin{array}{l}\text { Saya memperkirakan saya akan menggunakan fasilitas IT yang dapat membantu } \\
\text { saya berbagi pengetahuan dalam waktu dekat. }\end{array}$ & \\
\hline ATI3 & $\begin{array}{l}\text { Saya berencana menggunakan fasilitas IT yang dapat membantu saya berbagi } \\
\text { ilmu di masa depan yang dekat. }\end{array}$ & \\
\hline \multicolumn{2}{|r|}{ Knowledge Sharing (KS) } & Tseng (2017) \\
\hline $\mathrm{KS} 1$ & Saya berniat untuk berbagi pengetahuan saya dengan rekan-rekan saya. & \\
\hline KS2 & $\begin{array}{l}\text { Saya berniat untuk mencoba yang terbaik untuk berbagi pengetahuan saya } \\
\text { dengan rekan kerja saya }\end{array}$ & \\
\hline KS3 & $\begin{array}{l}\text { Saya bermaksud berusaha untuk berbagi pengetahuan saya dengan rekan-rekan } \\
\text { saya. }\end{array}$ & \\
\hline KS4 & $\begin{array}{l}\text { Saya berniat untuk berbagi pengetahuan saya dengan rekan-rekan saya lebih } \\
\text { sering di masa depan. }\end{array}$ & \\
\hline KS5 & $\begin{array}{l}\text { Saya berniat untuk berbagi pengetahuan saya dengan rekan-rekan saya di sebuah } \\
\text { cara yang efektif. }\end{array}$ & \\
\hline \multicolumn{2}{|r|}{ Dukungan Budaya Organisasi (DBO): } & Lukes \& \\
\hline DBO1 & $\begin{array}{l}\text { Kebanyakan orang di kampus memunculkan ide-ide baru dan orisinal di tempat } \\
\text { kerja. }\end{array}$ & $\begin{array}{l}\text { Stephan } \\
(2017)\end{array}$ \\
\hline $\mathrm{DBO} 2$ & $\begin{array}{l}\text { Kebanyakan orang di kampus benar-benar dapat menerapkan ide-ide baru di } \\
\text { tempat kerja. }\end{array}$ & \\
\hline
\end{tabular}


1352 Adopsi Teknologi Informasi dan Knowledge Sharing: Analisis Mediasi Budaya Organisasi di Perguruan Tinggi - Erni Taruli Pebrina, Rachma Nadhila Sudiyono, Suroso, Dewiana Novitasari, Masduki Asbari

DOI: https://doi.org/10.31004/edukatif.v4i1.2223

\begin{tabular}{lcc}
\hline Notasi & Item & Referensi \\
\hline DBO3 & Kebanyakan orang di kampus mencari tantangan baru di tempat kerja. & \\
DBO4 & Kebanyakan orang di kampus dapat berimprovisasi dengan mudah ketika terjadi & \\
& perubahan tak terduga di tempat kerja. & \\
\hline
\end{tabular}

Menurut Sekaran \& Bougie (2003) kerangka teoritis merupakan fondasi di mana seluruh proyek penelitian didasarkan. Dari kerangka teoritis bisa disusun hipotesis yang dapat diuji untuk mengetahui apakah teori yang dirumuskan valid atau tidak. Lalu kemudian selanjutnya akan dapat diukur dengan analisis statistik yang tepat. Untuk itu, penulis membangun model penelitian sebagai mana disebut pada Gambar 2 berikut:

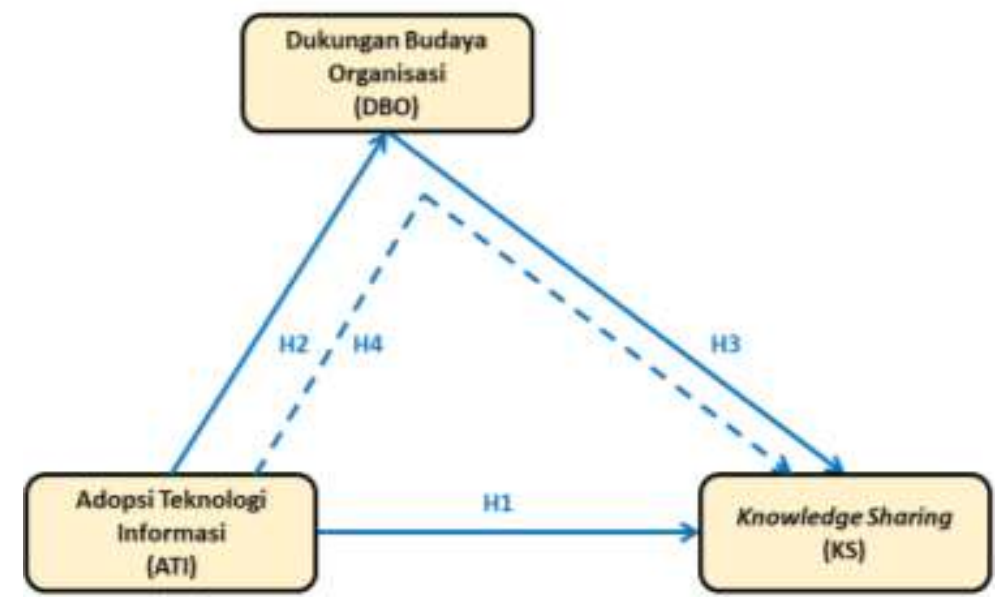

Gambar 2. Model Penelitian

Dengan demikian, penelitian ini menetapkan hipotesis sebagai berikut:

H1: Adopsi teknologi informasi memiliki pengaruh positif terhadap knowledge sharing.

H2: Adopsi teknologi informasi memiliki pengaruh positif terhadap dukungan budaya organisasi.

H3: Dukungan budaya organisasi memiliki pengaruh positif terhadap knowledge sharing.

H4: Adopsi teknologi informasi memiliki pengaruh positif secara tidak langsung terhadap knowledge sharing melalui mediasi dukungan budaya organisasi.

\section{HASIL DAN PEMBAHASAN}

\section{Hasil}

Total ada 102 dosen yang berpartisipasi. Paling banyak laki-laki (72.77\%), kemudian wanita (27.23\%). Mereka memiliki kelompok umur yang berbeda-beda, di bawah 30 tahun (25.41\%), berkisar antara 30-40 tahun (46.60\%), dan lebih dari 40 tahun (27.99\%). Masa kerja sebagai dosen juga beragam, sebagian di antaranya di bawah 5 tahun (35.66\%), berkisar antara 5-10 tahun (48.52\%), dan lebih dari 10 tahun (15.82\%).Pendidikan mayoritas adalah S2 (94.01\%), kemudian S3 (5.99\%).

Tahap pengujian model pengukuran meliputi pengujian validitas konvergen, validitas diskriminan. Sementara untuk menguji reliabilitas konstruk digunakan nilai cronbach's alpha dan composite reliability. Hasil analisis PLS dapat digunakan untuk menguji hipotesis penelitian jika seluruh indikator dalam model PLS telah memenuhi syarat validitas konvergen, validitas deskriminan dan uji reliabilitas. Uji validitas konvergen dilakukan dengan melihat nilai loading factor masing-masing indikator terhadap konstruknya. Pada sebagian besar referensi, bobot faktor sebesar 0,7 atau lebih dianggap memiliki validasi yang cukup kuat untuk menjelaskan konstruk laten (Chin, 1998; Ghozali, 2014; J. F. Hair et al., 2010). Pada penelitian ini batas minimal besarnya loading factor yang diterima adalah 0,7, dan dengan syarat nilai AVE setiap konstruk >0,5 (Ghozali, 2014). Setelah melalui pengolahan SmartPLS 3.0, seluruh indikator telah memiliki nilai loading factor di atas 0,7 dan nilai AVE di atas 0,5. Model fit atau valid dari penelitian ini dapat dilihat pada Gambar 
1353 Adopsi Teknologi Informasi dan Knowledge Sharing: Analisis Mediasi Budaya Organisasi di Perguruan Tinggi - Erni Taruli Pebrina, Rachma Nadhila Sudiyono, Suroso, Dewiana Novitasari, Masduki Asbari

DOI: https://doi.org/10.31004/edukatif.v4i1.2223

2. Jadi dengan demikian, validitas konvergen dari model penelitian ini sudah memenuhi syarat (Purwanto et al., 2019; Purwanto, Asbari, et al., 2020; Purwanto, Asbari, \& Santoso, 2021b, 2021a; Purwanto, Asbari, Santoso, et al., 2021). Nilai loadings, cronbach's alpha, composite reliability dan AVE setiap konstruk selengkapnya dapat dilihat Tabel 2.

Discriminant validity dilakukan untuk memastikan bahwa setiap konsep dari masing-masing variabel laten berbeda dengan variabel laten lainnya. Model mempunyai discriminant validity yang baik jika nilai kuadrat AVE masing-masing konstruk eksogen (nilai pada diagonal) melebihi korelasi antara konstruk tersebut dengan konstruk lainnya (nilai di bawah diagonal) (Ghozali, 2014). Hasil pengujian discriminant validity adalah dengan menggunakan nilai kuadrat AVE, yakni dengan melihat Fornell-Larcker Criterion Value diperoleh sebagaimana ditunjukkan pada Tabel 3. Hasil uji validitas deskriminan pada tabel 3 menunjukkan bahwa seluruh konstruk telah memiliki nilai akar kuadrat AVE di atas nilai korelasi dengan konstruk laten lainnya (melalui kriteria Fornell-Larcker). Demikian juga nilai cross-loading seluruh item dari suatu indikator lebih besar dari item indikator lainnya sebagaimana disebut pada Tabel 3, sehingga dapat disimpulkan bahwa model telah memenuhi validitas deskriminan (Fornell \& Larcker, 1981).

Selanjutnya dilakukan evaluasi collinearity untuk mengetahui ada tidaknya masalah collinearity pada model. Untuk menemukan collinearity tersebut, diperlukan statistik collinearity VIF dari setiap konstruk. Jika VIF lebih dari 5, maka model memiliki collinearity (Hair et al., 2014). Seperti yang ditunjukkan pada Tabel 4, semua skor VIF kurang dari 5, yakni hasil dari model struktural collinearity mengungkapkan nilai VIF di bawah 2. Hal ini menunjukkan bahwa model penelitian ini tidak ada masalah multikolinearitas.

Reliabilitas konstruk dapat dinilai dari nilai cronbach's alpha dan composite reliability dari masingmasing konstruk. Nilai composite reliability dan cronbach's alpha yang disarankan adalah lebih dari 0,7 (Ghozali, 2014). Hasil uji reliabilitas pada tabel 2 menunjukkan bahwa seluruh konstruk telah memiliki nilai composite reliability dan cronbach's alpha lebih besar dari $0,7(>0,7)$. Kesimpulannya, seluruh konstruk telah memenuhi reliabilitas yang dipersyaratkan.

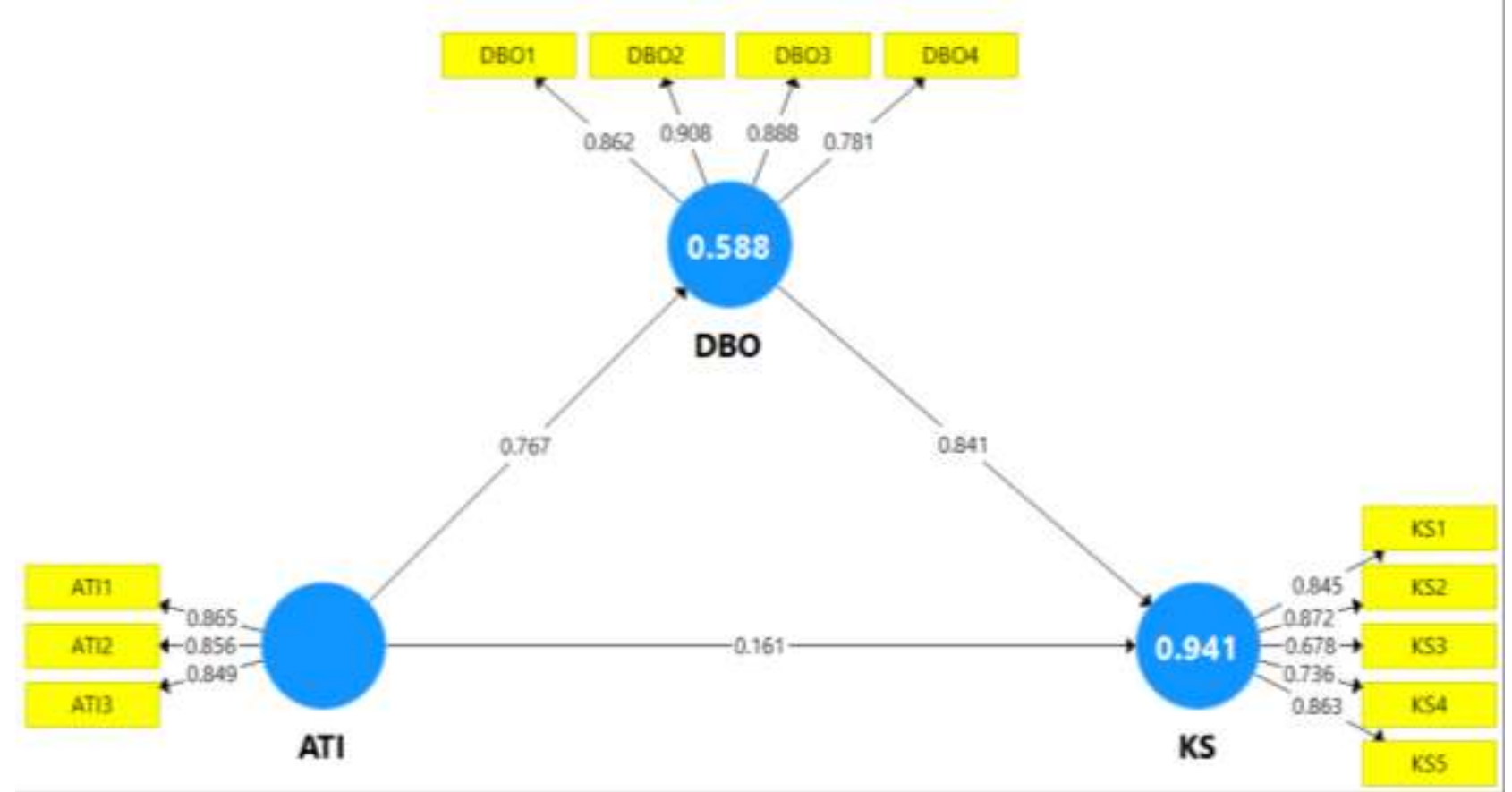

Gambar 2. Model Penelitian Valid

Sumber: Hasil Pengolahan SmartPLS 3.0 (2022) 
1354 Adopsi Teknologi Informasi dan Knowledge Sharing: Analisis Mediasi Budaya Organisasi di Perguruan Tinggi - Erni Taruli Pebrina, Rachma Nadhila Sudiyono, Suroso, Dewiana Novitasari, Masduki Asbari

DOI: https://doi.org/10.31004/edukatif.v4i1.2223

Tabel 2

Items Loadings, Cronbach's Alpha, Composite Reliability, and Average Variance Extracted (AVE)

\begin{tabular}{lcccccc}
\hline \multicolumn{1}{c}{ Variables } & Items & Loadings & $\begin{array}{c}\text { Cronbach's } \\
\text { Alpha }\end{array}$ & Rho_A & $\begin{array}{c}\text { Composite } \\
\text { Reliability }\end{array}$ & AVE \\
\hline Adopsi Teknologi Informasi (ATI) & ATI1 & 0,865 & 0,819 & 0,821 & 0,892 & 0,734 \\
& ATI2 & 0,856 & & & & \\
Knowledge Sharing (KS) & ATI3 & 0,849 & & & & \\
& KS1 & 0,845 & 0,883 & 0,890 & 0,920 & 0,742 \\
& KS2 & 0,872 & & & & \\
& KS3 & 0,678 & & & & \\
& KS4 & 0,736 & & & & \\
DS5 & 0,863 & & & & \\
& KS & & & \\
& DBO1 & 0,862 & 0,861 & 0,883 & 0,900 & 0,644 \\
& DBO2 & 0,908 & & & & \\
& DBO3 & 0,888 & & & & \\
& DBO4 & 0,781 & & & &
\end{tabular}

Sumber: Hasil Pengolahan SmartPLS 3.0 (2022)

Tabel 3

Discriminant Validity

\begin{tabular}{cccc}
\hline Variables & ATI & DBO & KS \\
\hline ATI & 0,857 & & \\
DBO & 0,767 & 0,861 & \\
KS & 0,806 & 0,965 & 0,803 \\
\hline \multicolumn{4}{l}{ Sumber: Hasil Pengolahan } \\
\end{tabular}

Tabel 4

Collinearity (VIF)

\begin{tabular}{cccc}
\hline Variables & ATI & DBO & KS \\
\hline ATI & & 1,000 & 2,427 \\
DBO & & & 2,427 \\
KS & & & \\
\hline
\end{tabular}

Sumber: Hasil Pengolahan SmartPLS 3.0 (2022)

Tabel 5

Nilai $R$ Square

\begin{tabular}{ccc}
\hline Variables & R Square & R Square Adjusted \\
\hline DBO & 0,588 & 0,585 \\
KS & 0,941 & 0,941 \\
\hline
\end{tabular}

Sumber: Hasil Pengolahan SmartPLS 3.0 (2022)

Tabel 6

Hypotheses Testing

\begin{tabular}{|c|c|c|c|c|c|c|c|}
\hline Hypotheses & Relationship & $\begin{array}{l}\text { Original } \\
\text { Sample } \\
\text { (O) }\end{array}$ & $\begin{array}{l}\text { Sample } \\
\text { Mean } \\
\text { (M) }\end{array}$ & $\begin{array}{l}\text { Standard } \\
\text { Deviation } \\
\text { (STDEV) }\end{array}$ & $\begin{array}{c}\text { T Statistics } \\
(|\mathrm{O} / \mathrm{STDEV}|)\end{array}$ & $\begin{array}{c}\mathrm{P} \\
\text { Values }\end{array}$ & Decision \\
\hline H1 & ATI $->\mathrm{KS}$ & 0,161 & 0,154 & 0,047 & & & Didukung \\
\hline $\mathrm{H} 2$ & ATI -> DBO & 0,767 & 0,768 & 0,040 & & 0,000 & Didukung \\
\hline $\mathrm{H} 3$ & DBO -> KS & 0,841 & 0,847 & 0,039 & 21,692 & 0,000 & Didukung \\
\hline $\mathrm{H} 4$ & ATI $->$ DBO $->\mathrm{KS}$ & 0,645 & 0,651 & 0,047 & 13,833 & 0,000 & Didukung \\
\hline
\end{tabular}

Sumber: Hasil Pengolahan SmartPLS 3.0 (2022) 
1355 Adopsi Teknologi Informasi dan Knowledge Sharing: Analisis Mediasi Budaya Organisasi di Perguruan Tinggi - Erni Taruli Pebrina, Rachma Nadhila Sudiyono, Suroso, Dewiana Novitasari, Masduki Asbari

DOI: https://doi.org/10.31004/edukatif.v4i1.2223

Pengujian hipotesis dalam PLS disebut juga sebagai uji inner model. Uji ini meliputi uji signifikansi pengaruh langsung dan tidak langsung serta pengukuran besarnya pengaruh variabel eksogen terhadap variabel endogen. Untuk mengetahui pengaruh Information Technology Adoption terhadap knowledge sharing intention dan dukungan budaya organisasi dibutuhkan uji pengaruh langsung. Uji pengaruh dilakukan dengan menggunakan uji t-statistik dalam model analisis partial least squared (PLS) dengan menggunakan bantuan software SmartPLS 3.0, Dengan teknik boothstrapping, diperoleh nilai $\mathrm{R}$ Square dan nilai uji signifikansi sebagaimana Tabel 5 dan Tabel 6. Hasilnya adalah semua hipotesis (H1, H2, H3, H4) di dukung.

\section{Pembahasan}

Berdasarkan Tabel 5, nilai R Square dukungan budaya organisasi (DBO) sebesar 0,588 yang berarti bahwa variable dukungan budaya organisasi (DBO) mampu dijelaskan oleh variabel adopsi teknologi informasi (ATI) sebesar 58,8\%, sedangkan sisanya sebesar 41,2\% dijelaskan oleh variabel lain yang tidak dibahas dalam penelitian ini. Sementara itu, nilai R Square knowledge sharing (KS) sebesar 0,941 yang berarti bahwa variable knowledge sharing (KS) mampu dijelaskan oleh variabel adopsi teknologi informasi (ATI) dan dukungan budaya organisasi (DBO) sebesar 94,1\%, sedangkan sisanya sebesar 5,9\% dijelaskan oleh variabel lain yang tidak dibahas dalam penelitian ini. Sedangkan Tabel 6 menampilkan t-statistics dan pvalues yang menunjukkan pengaruh antar variable penelitian yang telah disebutkan.

Tujuan utama dari penelitian ini adalah untuk menyelidiki pengaruh adopsi teknologi informasi terhadap knowledge sharing dengan mediasi variabel dukungan budaya organisasi. Hasil studi ini menyebutkan bahwa semua hipotesis didukung dan ditemukan fakta bahwa adopsi teknologi informasi berpengaruh positif dan signifikan terhadap knowledge sharing dan dukungan budaya organisasi. Demikian juga, dukungan budaya organisasi ternyata berperan positif dan signifikan sebagai mediator keduanya. Alhasil, penelitian ini menunjukkan bahwa dukungan budaya organisasi secara signifikan memoderasi hubungan antara adopsi TI dan knowledge sharing.

Namun demikian, penelitian ini juga bukannya tanpa batasan. Studi ini di masa depan perlu melibatkan factor jenis kelamin dan usi responden, sehingga bisa memtakan lebih detil setiap pengaruh dari dimensi kepemimpinan merek yang ada. Bisa jadi, temuan studi ini akan mengungkap fakta-fakta baru yang lebih rinci dan bermanfaat bagi perkembangan bisnis e-commerce di masa depan. Dimungkinkan juga untuk memperluas model teoritis studi ini dengan memasukkan variabel dependen tambahan seperti kepuasan konsumen dan budaya masyarakat.

\section{KESIMPULAN}

Akhirnya, temuan studi ini mengonfirmasi bahwa semua hipotesis didukung dan ditemukan fakta bahwa adopsi teknologi informasi berpengaruh positif dan signifikan terhadap knowledge sharing dan dukungan budaya organisasi. Demikian juga, dukungan budaya organisasi ternyata berperan positif dan signifikan sebagai mediator keduanya di kalangan dosen perguruan tinggi. Temuan dan implikasi dari studi ini sebagian besar sejalan dengan literatur yang ada, yang telah dibahas sebelumnya.

\section{DAFTAR PUSTAKA}

Aman, M., \& Asbari, M. (2020). Aplikasi SMS Gateway Berbasis Content Management System Untuk Sistem Informasi Sekolah. JIKEM: Jurnal Ilmu Komputer, Ekonomi Dan Manajemen, 1(1), 1-16.

Asbari, M., Novitasari, D., Purwanto, A., Fahmi, K., \& Setiawan, T. (2021). Self-leadership to Innovation: The Role of Knowledge Sharing. International Journal of Social and Management Studies (IJOSMAS), 02(05), 21-36. https://ijosmas.org/index.php/ijosmas/article/view/68

Chin, W. (1998). The Partial Least Squares Approach to Structural Equation Modeling (E. Modern Methods for Business Research, In: G. A. Marcoulides (ed.)). Lawrence Erlbaum Associates Publisher. 
1356 Adopsi Teknologi Informasi dan Knowledge Sharing: Analisis Mediasi Budaya Organisasi di Perguruan Tinggi - Erni Taruli Pebrina, Rachma Nadhila Sudiyono, Suroso, Dewiana Novitasari, Masduki Asbari

DOI: https://doi.org/10.31004/edukatif.v4i1.2223

Creswell, J. W., \& Creswell, J. D. (2017). Research design: Qualitative, quantitative, and mixed methods approaches. Sage publications.

Fathema, N., Shannon, D., \& Ross, M. (2015). Expanding the Technology Acceptance Model (TAM) to examine faculty use of Learning Management Systems (LMSs) in higher education institutions. Journal of Online Learning \& Teaching, 11(2).

Fikri, M. A. A., Pramono, T., Nugroho, Y. A., Novitasari, D., \& Asbari, M. (2021). Leadership Model in Pesantren: Managing Knowledge Sharing through Psychological Climate. International Journal of Social and Management Studies (IJOSMAS), 02(03), 149-160. https://ijosmas.org/index.php/ijosmas/article/view/44

Fornell, C., \& Larcker, D. F. (1981). Evaluating Structural Equation Models with Unobservable Variables and Measurement Error. Journal of Marketing Research, 18(1), 39. https://doi.org/10.2307/3151312

Ghozali, I. (2014). Structural Equation Modeling, Metode Alternatif dengan Partial Least Square (PLS) (4th ed.). Badan Penerbit Universitas Diponegoro.

Hair, J. F., Black, W. C., Babin, B. J., \& Anderson, R. E. (2010). Multivariate Data Analysis (7th ed.). Pearson Prentice Hall.

Hair, Joe F, Sarstedt, M., Ringle, C. M., \& Mena, J. A. (2012). An assessment of the use of partial least squares structural equation modeling in marketing research. Journal of the Academy of Marketing Science, 40(3), 414-433.

Hair Jr, J. F., Sarstedt, M., Ringle, C. M., \& Gudergan, S. P. (2017). Advanced issues in partial least squares structural equation modeling. saGe publications.

Hutagalung, D., Admiral, Nuryanti, Y., Asbari, M., \& Novitasari, D. (2021). Managing Tacit Knowledge Sharing: From Charismatic Leadership to Psychological Safety Climate. Inovbiz: Jurnal Inovasi Bisnis, 9(1), 108-119. https://doi.org/10.35314/inovbiz.v9i1.1888

Jarmooka, Q. (2021). The mapping of information and communication technologies, and knowledge management processes, with company innovation. Journal of Knowledge Management, 25(2), 313-335. https://doi.org/10.1108/JKM-01-2020-0061

Lukes, M., \& Stephan, U. (2017). Measuring Employee Innovation: A Review of Existing Scales and the Development of the Innovative Behavior and Innovation Support Inventories across Cultures. International Journal of Entrepreneurial Behavior \& Research, 23(1), 136-158. https://doi.org/10.1108/ijebr-11-2015-0262

Mohammadi, H. (2015). Investigating users' perspectives on e-learning: An integration of TAM and IS success model. Computers in Human Behavior, 45, 359-374. https://doi.org/10.1016/j.chb.2014.07.044

Novitasari, D., Haque, M. G., Supriatna, H., Asbari, M., \& Purwanto, A. (2021). Understanding the Links between Charismatic Leadership, Intrinsic Motivation and Tacit Knowledge Sharing among MSME Employees. International Journal of Social and Management Studies (IJOSMAS), 02(03), 1-13. https://www.ijosmas.org/index.php/ijosmas/article/view/29

Purwanto, A., Asbari, M., \& Santoso, T. I. (2021a). Analisis Data Penelitian Manajemen Pendidikan: Perbandingan Hasil antara Amos, SmartPLS, WarpPLS, dan SPSS untuk Jumlah Sampel Kecil. International Journal of Social, Policy and Law (IJOSPL), 01(01), 111-122.

https://ijospl.org/index.php/ijospl/article/view/64

Purwanto, A., Asbari, M., \& Santoso, T. I. (2021b). Education Management Research Data Analysis: Comparison of Results between Lisrel, Tetrad, GSCA, Amos, Smartpls, Warppls, And SPSS for Small Samples. Nidhomul Haq: Jurnal Manajemen Pendidikan Islam, 6(2), 382-399.

https://e-journal.ikhac.ac.id/index.php/nidhomulhaq/article/view/1575

Purwanto, A., Asbari, M., Santoso, T. I., Haque, M. G., \& Nurjaya. (2019). Marketing Research Quantitative 
1357 Adopsi Teknologi Informasi dan Knowledge Sharing: Analisis Mediasi Budaya Organisasi di Perguruan Tinggi - Erni Taruli Pebrina, Rachma Nadhila Sudiyono, Suroso, Dewiana Novitasari, Masduki Asbari

DOI: https://doi.org/10.31004/edukatif.v4i1.2223

Analysis for Large Sample: Comparing of Lisrel, Tetrad, GSCA, Amos, SmartPLS, WarpPLS, and SPSS. Jurnal Ilmiah Ilmu Administrasi Publik: Jurnal Pemikiran Dan Penelitian Administrasi Publik, 9(2), 355-372. https://ojs.unm.ac.id/iap/article/view/22803

Purwanto, A., Asbari, M., Santoso, T. I., Paramarta, V., \& Sunarsih, D. (2020). Social and Management Research Quantitative Analysis for Medium Sample: Comparing of Lisrel, Tetrad, GSCA, Amos, SmartPLS, WarpPLS, and SPSS. Jurnal Ilmiah Ilmu Administrasi Publik: Jurnal Pemikiran Dan Penelitian Administrasi Publik, 9(2), 518-532. https://ojs.unm.ac.id/iap/article/view/22804

Purwanto, A., Asbari, M., Santoso, T. I., Sunarsi, D., \& Ilham, D. (2021). Education Research Quantitative Analysis for Little Respondents: Comparing of Lisrel, Tetrad, GSCA, Amos, SmartPLS, WarpPLS, and SPSS. Jurnal Studi Guru Dan Pembelajaran, 4(2), 335-350.

https://e-journal.my.id/jsgp/article/view/1326

Purwanto, A., Bernarto, I., Asbari, M., Mayesti Wijayanti, L., \& Chi Hyun, C. (2020). Effect of Transformational and Transactional Leadership Style on Public Health Centre Performance. Journal of Reseacrh in Business, Economics, and Education, 2(1), 304-314.

http://e-journal.stie-kusumanegara.ac.id

Roscoe, A. M., Lang, D., \& Sheth, J. N. (1975). Follow-up Methods, Questionnaire Length, and Market Differences in Mail Surveys: In this experimental test, a telephone reminder produced the best response rate and questionnaire length had no effect on rate of return. Journal of Marketing, 39(2), 20-27.

Sarstedt, M., Ringle, C. M., Smith, D., Reams, R., \& Hair Jr, J. F. (2014). Partial least squares structural equation modeling (PLS-SEM): A useful tool for family business researchers. Journal of Family Business Strategy, 5(1), 105-115.

Sekaran, U., \& Bougie, R. (2003). Research Methods For Business: A Skill Building Approach (Sixth edit). John Wiley and Sons, Inc.

Singgih, E., Iskandar, J., Goestjahjanti, F. S., Fahlevi, M., Nadeak, M., Fahmi, K., Anwar, R., Asbari, M., \& Purwanto, A. (2020). The Role of Job Satisfaction in the Relationship between Transformational Leadership, Knowledge Management, Work Environment and Performance. Solid State Technology, 63(2s), 293-314. http://www.solidstatetechnology.us/index.php/JSST/article/view/1556

Soto-Acosta, P. (2018). Information technology, knowledge management and environmental dynamism as drivers of innovation ambidexterity: a study in SMEs. Journal of Knowledge Management, 22(4), 824849. https://doi.org/10.1108/JKM-10-2017-0448

Suroso, Novitasari, D., Nugroho, Y. A., Chidir, G., \& Asbari, M. (2021). Managing MSME Innovation Performance: Analysis of Knowledge-Oriented Leadership and Knowledge Management Capability. Edukatif: Jurnal Ilmu Pendidikan, 3(6), 4541-4555. https://edukatif.org/index.php/edukatif/article/view/1506

Tiara, B., Stefanny, V., Sukriyah, Novitasari, D., \& Asbari, M. (2021). Inovasi di Era Informasi: Analisis Kepemimpinan Transformasional dan Iklim Etis di Industri Manufaktur. Edukatif: Jurnal Ilmu Pendidikan, 3(6), 4651-4660.

Tseng, S. M. (2017). Investigating the moderating effects of organizational culture and leadership style on ITadoption and knowledge-sharing intention. Journal of Enterprise Information Management, 30(4), 583 604. https://doi.org/10.1108/JEIM-04-2016-0081 